\title{
Processo criativo na indústria do audiovisual: do roteiro ao imaginário ${ }^{1}$
}

\author{
Sílvio Antonio Luiz Anaz' \\ I - USP \\ São Paulo (SP), Brasil
}

Resumo: O processo de criação na indústria do audiovisual desenvolve-se por meio da articulação de vários agentes (roteiristas, diretores, produtores, executivos, elencos etc.), tecnologias e decisões corporativas. Estudar o processo criativo nessa indústria requer compreender como esses elementos, que imiscuem arte e negócios, impactam na construção dos imaginários que filmes e séries compartilham com a audiência. Este artigo busca contribuir para a compreensão desse processo, que se desenvolve de forma coletiva e sob a lógica do mercado, tendo como base a perspectiva heurística do imaginário (Eliade, Durand, Barros), o conceito de arquétipo (Jung) e o método mitocrítico. Os resultados são o mapeamento do processo de criação e o esboço de um método para o estudo do processo criativo na indústria do audiovisual.

Palavras-chave: processo criativo; imaginário; indústria do audiovisual; mitocrítica.

Abstract: Creative process in the audiovisual industry: from script to the imaginary - The creative process in the audiovisual industry is based on coordination among several agents (screenwriters, directors, producers, executives, casts, etc.), technologies and corporate decisions. Studying this process requires an understanding of how those elements, that blend art and business, impact the development of the imaginary that movies and TV series share with audiences. This paper seeks to contribute toward an understanding of this process, which is developed collectively and under market logic, based on a heuristic perspective of the imaginary (Eliade, Durand, Barros), the archetypological concept (Jung, Durand), and the mythocritical method. The results are the mapping of the creative process and the draft of a method for investigation of the process in the audiovisual industry.

Keywords: creative process; imaginary; audiovisual industry; mythocriticism.

1 Esta investigação teve o apoio da FAPESP e da CAPES (Processo 2014/13330-1). O autor é res-ponsável pelas opiniões, hipóteses, conclusões e recomendações expressas neste artigo e elas não refletem necessariamente os pontos de vista da FAPESP e CAPES. 


\section{Processo de criação coletivo, segmentado e complexo}

O estudo do processo de criação na indústria do audiovisual envolve analisar a intricada combinação de elementos que compõem a produção de filmes e séries. Diferentemente de grande parte das obras da literatura e das artes visuais, por exemplo, em que apenas um ou poucos criadores atuam ao longo de todo o processo criativo e, consequentemente, exercem amplo controle sobre o produto final, na indústria do audiovisual o processo de criação desenvolve-se de forma coletiva e segmentada, resultado da articulação de diversos profissionais, recursos tecnológicos e interesses corporativos.

A complexidade do processo criativo das narrativas audiovisuais, sejam elas pensadas originalmente para cinema, televisão ou streaming, deve-se essencialmente à sua dinâmica, com a participação de diversos profissionais especializados atuando de forma segmentada e hierárquica. Assim, o processo exige a articulação de vários agentes - como roteiristas, diretores, produtores, executivos, editores e elencos -, técnicas, recursos tecnológicos e decisões corporativas, que refletem intenções e interesses artísticos, comerciais e institucionais. Além disso, é um processo que se estende ao longo de várias etapas da ideia inicial e elaboração da primeira versão de um roteiro à edição final, pelo menos -, nas quais a narrativa ganha novas características. É preciso ainda destacar que a investigação do processo criativo nesse contexto envolve considerar a constante interface da criação com os processos de tomada de decisões das corporações da mídia.

A tese inicial aqui defendida é que a compreensão dessa dinâmica deve ser feita com base em duas perspectivas que são complementares: o caminho que o roteiro percorre e a construção do imaginário que emerge dele.

A primeira perspectiva identifica as trajetórias que o roteiro trilha em clusters cinematográficos e televisivos, formado por estúdios, produtoras e emissoras, voltados a mercados nacionais e globais, como os de Los Angeles e Nova York. Tal trajetória pode ser visualizada no fluxograma (Figura 1) que compreende a parte do processo de criação relativa à elaboração do roteiro, desde o primeiro rascunho (first draft) até a versão para filmagem (shooting script).

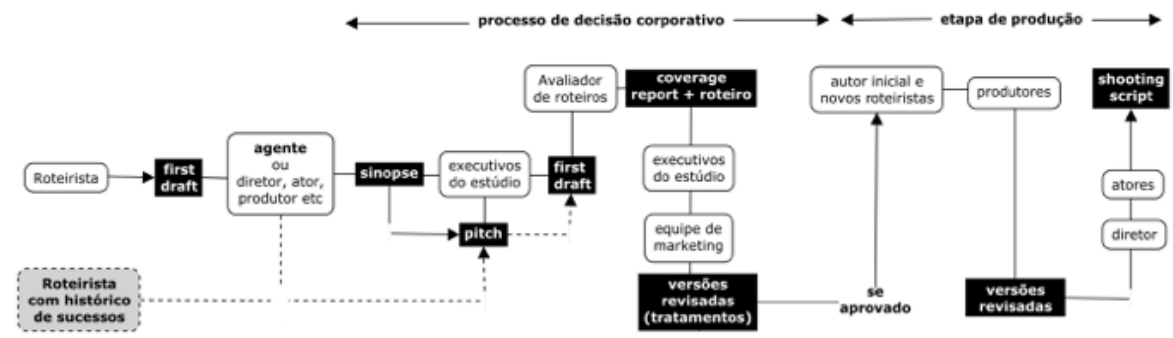

Fig. 1. Fluxograma geral de um roteiro na indústria do audiovisual. Fonte: ANAZ (2016, p. 141). 
Em geral, o roteiro após ser adquirido por um estúdio, produtora ou emissora fica sujeito a várias modificações, que podem ser feitas por diversos agentes em diferentes graus: roteiristas, diretores, executivos, produtores e elenco. Há basicamente duas instâncias no processo de criação do roteiro, após ele ser comprado ou o roteirista comissionado para desenvolvê-lo: uma relativa à pré-produção e ao processo de decisão corporativa e outra referente à etapa de produção.

No processo de decisão corporativa até o sinal verde para a produção, envolvem-se principalmente o roteirista - normalmente comissionado para fazer um determinado número de versões revisadas do roteiro-, os executivos do estúdio, produtora e emissora e suas equipes, diretor e produtores executivos. A partir da aprovação, o roteiro entra na fase de produção e, além do roteirista inicial, novos roteiristas, diretor, elenco e produtores também podem contribuir com sugestões que o modifiquem. Nessa fase, as decisões corporativas continuam a impactar nele, visando sempre a aumentar seu potencial de sucesso e adequá-lo em relação à classificação etária e aos interesses institucionais do estúdio ou emissora.

Há de se considerar ainda que na lógica de negócios em que se insere a maior parte dos produtos da indústria do audiovisual, decisões corporativas e em relação ao conteúdo e formato ocorrem fora dos âmbitos do roteirista e do diretor e pautam-se pelo interesse econômico de se obter a maior lucratividade e/ou o maior prestígio possível com o produto em desenvolvimento. A mentalidade comercial que dá ao filme ou à série de TV características mais palatáveis - em relação a determinados segmentos da audiência, aos patrocinadores e/ou aos órgãos de classificação etária, por exemplo - é aplicada ao produto em diferentes graus e em diferentes etapas por diferentes participantes do processo. Alguns dos possíveis resultados disso envolvem amenizar eventuais ousadias das primeiras versões do roteiro e, em situações incontornáveis, redirecionar a produção para segmentos alternativos.

Essa visão geral do processo de criação do roteiro, dada a sua dinâmica, pode se desenvolver com algumas variações, dependendo das características do projeto e do contexto econômico e sociocultural em que a indústria do audiovisual está inserida.

A segunda perspectiva para compreender a dinâmica do processo de criação na indústria do audiovisual é a da construção do imaginário que emerge da narrativa. Tal imaginário é entendido, baseado nos conceitos de Gilbert Durand, como o conjunto articulado de elementos simbólicos (imagens simbólicas, arquétipos, estereótipos e mitos) que constroem os sentidos do filme ou série e materializam-se nas imagens e sons compartilhados com a audiência. Mas, antes de materializar-se, o imaginário é fruto, na concepção de Durand (2002), de um trajeto antropológico ${ }^{2}$ no qual os elementos simbólicos emergem. Mas, como destaca Barros (2016), o imaginário é também uma perspectiva heurística para o estudo dos produtos e processos comunicacionais:

2 Durand (2002) define o trajeto antropológico como o percurso que une os gestos humanos básicos (postural, digestivo e copulativo) a estruturas e esquemas psicológicos figurativos e ao mundo externo. Nesse trajeto de mão dupla, situado entre as pulsões e as coerções, se dá a produção do imaginário, condicionada pela interação das características biopsíquicas do homo sapiens com as dos mundos natural e cultural. 
É possível estudar empiricamente o imaginário porque ele se epifaniza em cada manifestação criativa, sendo a menor de suas unidades detectáveis a imagem simbólica. Para encontrá-la, são necessárias ferramentas teóricas e metodológicas específicas, resultantes de uma heurística peculiar ao entendimento que se tem sobre o que seja o imaginário (BARROS, 2016, p. 350).

Nessa perspectiva, o imaginário compartilhado por um filme ou série tem sua espinha dorsal estabelecida pelo roteiro, mas ganha novas camadas e definições nas diferentes etapas do processo de criação na lógica que rege a indústria do audiovisual. O roteiro inicial e as versões desenvolvidas ao longo de sua trajetória no processo criativo (Figura 1) estabelecem a estrutura arquetípica que incute nos agentes participantes os elementos simbólicos que fundamentam o imaginário da narrativa. O imaginário insinuado pela estrutura arquetípica se consolida por meio de camadas que lhe são acrescidas nas diferentes etapas do processo de criação e pelos diversos profissionais especializados envolvidos em cada uma delas. Além disso, a construção do imaginário se dá nos sentidos diacrônico, à medida que as etapas avançam em direção aos produtos finais, e sincrônico, em função da simultaneidade de algumas tarefas pertencentes a etapas distintas.

O diagrama (Figura 2) busca retratar o processo de construção do imaginário nas produções audiovisuais, dividindo-o em seis etapas principais: roteiro inicial, roteiro revisado, filmagem, edição, marketing e transmídia e indicando os principais profissionais e recursos que delas participam contribuindo com a materialização do imaginário.

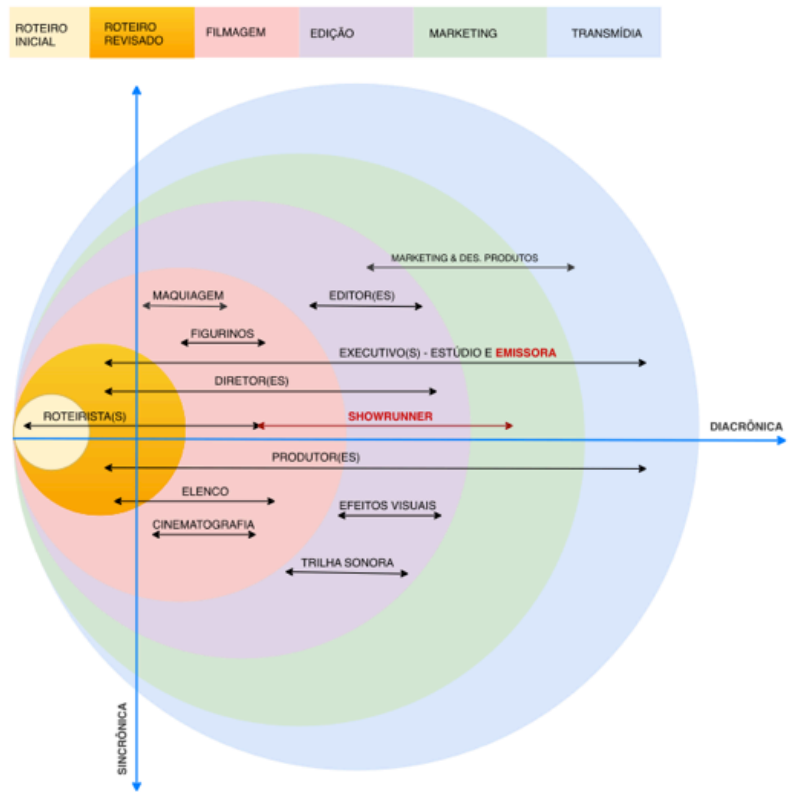

Fig. 2. Construção do imaginário no processo criativo na indústria do audiovisual Fonte: Elaborado pelo autor. 
No mapeamento que o diagrama faz do processo de construção do imaginário, evidenciam-se algumas de suas características centrais: o de ser um processo complexo com múltiplos colaboradores-criadores; de ser segmentado, mas interconectado; e de não haver nele uma função que participe de todas as etapas, nem mesmo os executivos ou produtores participam ou exercem um pleno controle sobre todas elas - salvo exceções, como quando o roteirista original assume a função de produtor executivo e/ou showrunner.

Nas duas perspectivas apresentadas e que se complementam - a do trajeto do roteiro e a da construção do imaginário -, o roteiro é não só o ponto de partida como também a espinha dorsal de todo o processo criativo na indústria do audiovisual. A importância do roteiro na tese aqui defendida é que ele oferece ao processo de criação, como um todo, uma estrutura arquetípica que irá orientá-lo.

\section{Estrutura arquetípica}

É no roteiro que se encontra o conjunto de elementos simbólicos que estabelece a estrutura arquetípica da narrativa, isto é, a forma como esse conjunto de elementos, dentre os quais destacam-se os arquétipos e estereótipos, com suas funções dramáticas e psicológicas, articula-se para contar uma determinada história e estabelecer o núcleo do imaginário que o autor propõe compartilhar com a audiência.

Apesar de materializar-se em palavras, um roteiro para um filme ou uma série de TV é pensado a partir de imagens e destina-se principalmente a construir imagens. As imagens mentalizadas pelo criador são por meio do roteiro transmitidas e recriadas pelos demais interlocutores na produção de uma obra audiovisual, como diretor, elenco, figurinistas, maquiadores, editores, produtores e executivos do estúdio, até ser finalmente materializada na tela e compartilhada com a audiência.

Ao longo de todo o processo, e de forma cíclica - afinal os participantes são ao mesmo tempo produtores e consumidores das imagens -, a imaginação de cada agente opera traduzindo e recriando as informações apresentadas a ela: a imagem mentalizada pelo roteirista é traduzida em palavras no roteiro; as palavras são então traduzidas em imagens pelos demais participantes do processo até serem materializadas, primeiro em storyboards e/ou croquis, e depois nas imagens e sons que compõem a obra; por fim, as imagens materializadas e projetadas na tela em conjunto com o áudio serão (re)interpretadas pela audiência.

As imagens arquetípicas atravessam todo o processo comunicacional e parecem ser o elemento-chave na eficiência dele. Em um processo eficiente, as imagens e símbolos mentalizados pelo roteirista, como as que remetem ao arquétipo do herói, por exemplo, transformam-se em ideias e palavras no roteiro, que por sua vez serão recriadas sucessivamente até serem materializada na tela para finalmente serem interpretadas como a imagem de um herói pela audiência. 
A compreensão do funcionamento desse processo começa por entender o papel do arquétipo na perspectiva junguiana. O arquétipo em si é definido por Jung (1970) como uma possibilidade de manifestação e concretização de imagens e símbolos, como se fosse uma forma básica. Imagem primordial, universal e a-histórica, o arquétipo é, assim, um molde vazio que pode ser preenchido por diferentes imagens em diferentes culturas, mas com todas remetendo ao mesmo significado arquetípico.

Durand (2002) coloca o conceito de arquétipo junguiano como um dos elementos centrais de sua teoria geral do imaginário. No entanto, diferentemente de Jung que considera o arquétipo como forma herdada e básica, Durand o insere como elemento intermediário do trajeto antropológico conectado a gestos biológicos (postural, digestivo e copulativo), estes sim básicos, e a esquemas e estruturas psicológicas. A hipótese de Durand explica a origem do arquétipo em uma perspectiva antropológica e o coloca com uma função intermediária, como elemento conector entre os mundos interno do homem (biopsíquico) e o externo (natural e cultural).

É preciso ressaltar também a ambivalência do arquétipo enquanto forma vazia que é. Exemplo disso é dado por um dos arquétipos descritos por Jung: o materno, que traz em si os opostos da mãe amante (positivo), fonte de forças que promovem crescimento pessoal, criatividade e auto-realização, e da mãe medonha (negativo), que se manifesta como fator limitante, retentivo e inibidor do desenvolvimento (HARK, 2000, p. 23).

O conceito junguiano de arquétipo mostra-se bastante eficiente quando aplicado na criação e análise das narrativas audiovisuais. Conceito que está assimilado por toda a cadeia produtiva do cinema norte-americano (das universidades aos grandes estúdios), cuja produção mainstream domina cerca de dois terços do mercado cinematográfico global.

Jung (1970), Campbell (1997), Eliade (1992) e Durand (2002) descrevem em seus trabalhos alguns dos arquétipos encontrados em elementos da psicanálise e em amplos recenseamentos da produção cultural global, o que inclui mitologias, contos folclóricos, romances e obras das artes visuais. Apesar de hipoteticamente existirem a priori no nível do inconsciente, os arquétipos só podem ser identificados e descritos a posteriori, a partir de sua manifestação, ou seja, a partir de seu preenchimento de forma universal e a-histórica. O arquétipo em si é algo irrepresentável (JUNG, 1970) e o que é identificável é a imagem arquetípica, isto é, o molde que estava vazio (arquétipo irrepresentável) e que foi preenchido por (diferentes) imagens simbólicas (ou símbolos) em diferentes culturas, mas com significados similares que remetem ao mesmo arquétipo. Significado este que é intrínseco à imagem arquetípica, em função de sua pregnância simbólica, isto é, do fato de que um dado sensível, como a imagem arquetípica, não surge ao sujeito de forma pura, mas sim impregnada de sentidos (CASSIRER, 1929, p. 238). Tal significado, portanto, não é estabelecido de forma arbitrária, ao contrário do que ocorre com a palavra e os signos.

É preciso ainda destacar dois pontos sobre os arquétipos nas narrativas audiovisuais: o primeiro é que não há necessariamente uma unicidade entre o personagem e determinado 
arquétipo, pois um personagem pode ser composto por vários arquétipos e um mesmo arquétipo pode aparecer em vários personagens, numa mesma narrativa; o segundo é que a estrutura arquetípica pode ser ocupada por arquétipos e estereótipos, sendo estes uma degradação dos primeiros, isto é, o estereótipo é a representação de um único aspecto ou de uma parte apenas do arquétipo, que elimina sua dinâmica e bivalência interna. Enquanto a composição de um personagem com vários arquétipos, com suas ambiguidades, colabora para a construção de uma representação mais completa e complexa (personagens redondos ou tridimensionais), a construção de personagens com um único arquétipo ou como um estereótipo resulta em uma representação simplificadora (personagens planos ou unidimensionais).

Em filmes ou séries, a estrutura arquetípica atravessa toda a narrativa e normalmente orienta os subprodutos correlatos e transmidiáticos, que expandem o universo original, como trailers, spin-offs, quadrinhos e jogos, entre outros.

Em cada filme ou episódio, a estrutura arquetípica revela o(s) enredo(s) medular(es) da narrativa e os arquétipos e estereótipos que compõem o núcleo do imaginário e as suas conexões. Característica frequente da estrutura arquetípica de um roteiro audiovisual é ser reprodução ou atualização de um acervo restrito de protótipos de narrativas produzidos pela imaginação do homo sapiens ao longo de sua existência. O número limitado de padrões no contar histórias tem sido identificado de diferentes formas e de fontes diversas, por estudiosos das narrativas como Propp (2006), Campbell (1997), Frye e Macpherson (2004), Vogler (2006) e Booker (2010).

Um dos padrões mais frequentes é o do herói vence o monstro que resulta, por exemplo, na estrutura arquetípica encontrada em Guerra nas estrelas: Uma nova esperança (Figura 3):

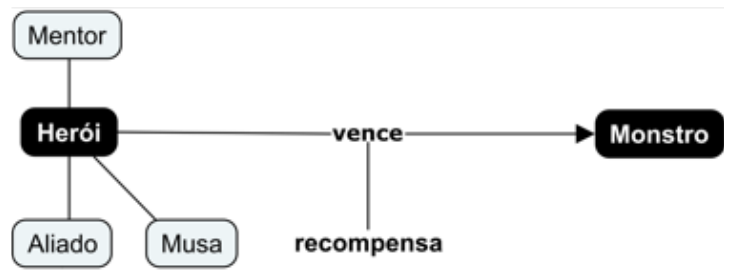

Fig. 3. Estrutura arquetípica de Guerra nas estrelas: Uma nova esperança. Fonte: Elaborado pelo autor.

O primeiro filme da saga Guerra nas Estrelas tem como enredo básico a aventura de Luke Skywalker (herói) que luta e derrota Darth Vader (monstro), alcançando como recompensa salvar a Princesa Léa (musa) e a Aliança Rebelde e ganhar a admiração deles. Em sua jornada, o herói interage principalmente com o mentor (Obi-Wan Kenobi), os aliados (Han Solo, Chewbaca, R2D2, C3PO) e a musa. É interessante destacar que a mesma estrutura arquetípica, ainda que com outros personagens, irá se repetir nos demais seis filmes da saga lançados até 2015. 
As estruturas arquetípicas que refletem o enredo do herói que derrota o monstro predominam amplamente nas produções de ação, aventura, ficção científica e fantasia que têm dominado as bilheterias cinematográficas nas primeiras décadas do século 21. Segundo Booker (2004), a estrutura narrativa que traz um herói que é chamado para enfrentar e derrotar uma terrível e mortal personificação do mal é a que parece se formar mais naturalmente na imaginação humana. Esse enredo básico está presente em praticamente todos os gêneros audiovisuais.

Ele pode ser observado também em Blade Runner, o caçador de androides (Ridley Scott, 1982) ${ }^{3}$. No filme, o enredo herói vence o monstro também compõe o eixo central da estrutura arquetípica, embora de forma variada já que ela é atravessada por outro tema: o monstro como herói, conforme mostra o diagrama (Figura 4):

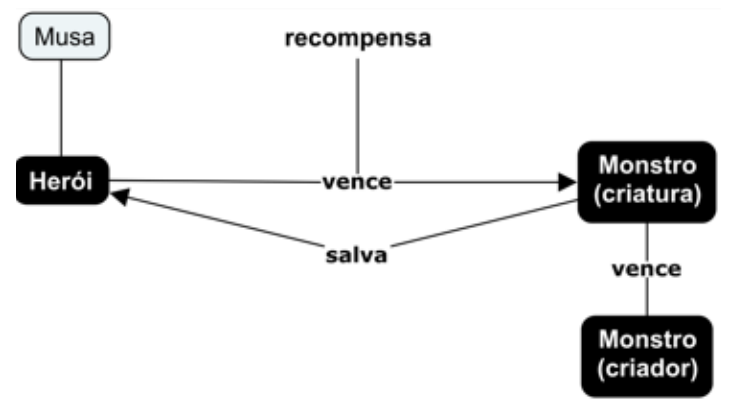

Fig. 4. Estrutura arquetípica de Blade Runner Fonte: Elaborado pelo autor.

Em Blade Runner, o caçador de androides, o enredo básico traz Rick Deckard (herói), um caçador de androides em um futuro distópico, que persegue e elimina um grupo de androides rebelados (monstros), liderados pelo replicante Roy Batty. A recompensa de Deckard é a fuga com a replicante Rachel, por quem o herói se apaixona. Essa estrutura, no entanto, é complementada por outra em que o monstro (Roy Batty) salva o herói (Rick Deckard). Há também a duplicação da estrutura principal - herói vence o monstro na parte da narrativa em que a criatura (Roy Batty) busca e assassina o criador (Eldon Tyrrel, cientista-empresário, proprietário da tecnologia dos androides). Na sua trajetória quase solitária, o herói conta essencialmente com a ajuda da musa (Rachel).

As estruturas arquetípicas consolidadas nas versões finais das narrativas podem ou não ter sido modificadas ao longo dos processos criativos. Em Guerra nas estrelas: Uma nova esperança e Blade Runner, o caçador de androides, ainda que tenham recebido modificações em maior ou menor grau desde o primeiro roteiro até o produto final, as estruturas arquetípicas permaneceram essencialmente as mesmas ao longo de todo o processo (ANAZ, 2016, p. 165).

3 A versão do filme utilizada nesta análise foi a lançada nos cinemas internacionalmente em 1982-1983 (international theatrical version). 
Identificar a estrutura arquetípica e como ela é construída ao longo do percurso da criação do roteiro contribui para a compreensão do imaginário que é engendrado no processo criativo. $\mathrm{O}$ estudo desse processo por meio de rastros ${ }^{4}$ deixados nas versões de um roteiro e sua comparação com a obra final dá conta da compreensão de uma parte significativa do processo de criação na indústria do audiovisual (ANAZ, 2016). Mas, isso não basta e é preciso ir além.

O imaginário compartilhado pela narrativa audiovisual tem a estrutura estabelecida pelo roteiro, mas a materialização dos elementos simbólicos ocorre ao longo das demais etapas do processo de criação (filmagem, edição, marketing, transmídia). Para compreender como o imaginário se materializa no processo criativo é preciso antes identificar qual é o imaginário que foi materializado e quais são os elementos centrais desse imaginário que foram trabalhados ao longo da criação.

\section{Mitema como elemento básico no estudo do processo criativo}

Mircea Eliade (1992, 1998), Northrop Frye (1973), Michel Maffesoli (2010) e Gilbert Durand (1985, 2004, 2012), em diferentes perspectivas, defendem a tese de que os discursos e as narrativas (não-míticas) têm nos mitos suas matrizes. Consequentemente, discursos e narrativas estabelecem diferentes graus de parentesco e correlação com os relatos míticos e são por eles orientados ou desorientados. As obras culturais (literárias, dramatúrgicas, visuais, cinematográficas etc.) trazem, assim, resíduos de elementos míticos e a ação de identificá-los e analisá-los criticamente contribui para uma compreensão dos significados que a obra abre ao seu leitor ou audiência. Tal ação é chamada de mitocrítica.

Durand deu à mitocrítica o status de método científico ao estabelecer nos anos 1970 um conjunto de procedimentos para sua realização. Nos artigos Sobre a exploração do imaginário: seu vocabulário, métodos e aplicações transdisciplinares (DURAND, 1985), O retorno do mito: introdução à mitodologia (DURAND, 2004) e Passo a passo mitocrítico (DURAND, 2012), o pensador francês apresenta as premissas e demonstra a aplicabilidade de seu método.

Entendemos que a mitocrítica pauta-se por uma hermenêutica de construção de sentidos com base naquilo que a obra propõe. O método não busca encontrar supostos segredos que a obra esconde. Ele é uma ação interpretativa que procura, como afirma Paul Ricoeur, não o que se dissimula por detrás do texto, mas sim a proposição diante do texto: "interpretar é explicitar o tipo de ser-no-mundo manifestado diante do texto" (RICOEUR, 1990, p. 56). Assim, o que a mitocrítica proporciona é vislumbrar a atualização que a obra faz das lições míticas que ela traz.

4 A ideia de rastros aqui é tomada emprestada da crítica genética: "Se o propósito direcionador dos estudos genéticos foi, desde seu início, a compreensão do processo de construção de uma obra literária e se seu objeto de estudo eram as pegadas do escritor encontradas nos manuscritos, deveria necessariamente romper a barreira da literatura e ampliar seus limites para além da palavra. Processo e pegadas são independentes da materialidade na qual a obra se manifesta e independentes, também, das linguagens nas quais essas pegadas se apresentam. É possível, portanto, conhecer alguns dos mecanismos da criação, em qualquer manifestação artística a partir dos rastros deixados pelos artistas" (SALLES, 2002, p. 62). 
Admitida a perspectiva que as obras audiovisuais são obsedadas por mitos, os imaginários que emergem de filmes e séries trazem reminiscências de mitos fundadores de sociedades e épocas. Esses resquícios míticos são os mitemas, isto é, as menores unidades semânticas que remetem aos mitos que assediam a narrativa e que são identificáveis por meio da mitocrítica.

Se toda narrativa tem no mito sua matriz e se o mitema é a reminiscência do mito que está presente desde o início do processo de criação, isto é, desde as primeiras ideias e/ou primeiros roteiros, e compõe o núcleo do imaginário que o produto final compartilha com a audiência, o mitema constitui-se, assim, em elemento básico do imaginário que emerge da narrativa.

Apoiada nessa premissa, a tese aqui proposta é a de que o estudo do processo de criação da narrativa audiovisual pode ser feito de forma eficiente por meio da investigação da construção dos mitemas nas diversas etapas que compõem a indústria do audiovisual. Isso porque ao atravessar todas as etapas do processo criativo, dos roteiros iniciais às ações de marketing e expansões transmidiáticas, cada mitema é trabalhado sucessivamente, tornando-se elemento que pode ser tomado como base para o estudo do processo criativo.

Vejamos a seguir um exemplo tirado da primeira temporada de sense8 (The Wachowski e J. Michael Straczynski, 2015) ${ }^{5}$.

A estrutura arquetípica da série reflete o enredo herói vence o monstro, com uma variação importante: o herói não é um único personagem, mas sim um amalgama de oito protagonistas, que com habilidades específicas e diferentes características (étnicas, religiosas, sexuais, sociais, temperamentais) se complementam (Figura 5).

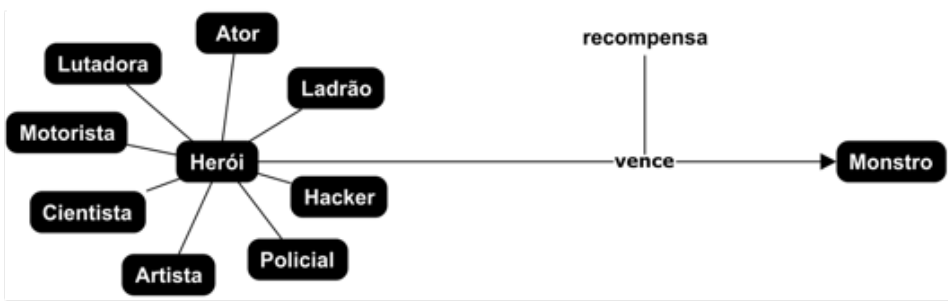

Fig.5. Estrutura arquetípica em sense8 (primeira temporada).

Fonte: Elaborado pelo autor.

A mitocrítica do primeiro ano da série mostra que seu imaginário é composto por oito mitemas: busca da completude, diversidade, duplicidade (máscara), heroísmo, mancha (sombra), prazer, relações familiares e sagrado. Dentre eles, destaca-se o da busca da completude, por seu papel central na estrutura arquetípica. É nele que focamos neste exemplo.

O mitema da busca da completude na série refere-se às diferenças (físicas, emocionais, sexuais, espirituais, sociais) entre cada protagonista e à necessidade que cada um tem

5 Produzida pela Netflix, a primeira temporada da série sense 8 conta a história de um grupo de oito pessoas que vivem em diferentes partes do mundo (São Francisco, Chicago, Cidade do México, Londres, Berlim, Nairóbi, Seul e Mumbai) e que não se conhecem, mas que repentinamente começam a estabelecer conexões mentais e emocionais à distância, o que as faz se ajudarem em várias situações, enquanto são perseguidas por uma organização secreta. 
do Outro, pois é a integração de características diversas e a harmonia com o Outro que tornam os personagens (quase) completos. A análise mitocrítica indica que o mitema da busca da completude em sense8 correlaciona-se com o mito do Andrógino (PLATÃO, 2012), ao atualizar as lições míticas da procura por aquilo que está ausente e pela reconstrução da unidade perdida, e com o mito de Dioniso (VERNANT, 2000), ao atualizar as lições da introdução do diferente no Cosmos e da incorporação do estigmatizado à sociedade.

Tendo como ponto de chegada os sentidos que um mitema traz para o imaginário, o estudo do processo criativo pode, então, investigar os documentos referentes às etapas de criação, assim como os rastros deixados por elas. O investigador deve considerar também a análise de aspectos da filmagem - como direção, uso de técnicas (truques de câmera, iluminação, tomadas de cenas etc.) e performance do elenco - e da edição (trilha sonora, cortes etc.), assim como informações e produtos da etapa de marketing e, quando for o caso, da etapa de expansão transmidiática do universo narrativo.

No caso do mitema da busca da completude, em sense8, ele já aparece como elemento central nas ideias que alimentaram a elaboração dos roteiros. Evidências disso estão na proposta de Lana Wachowski de criar uma narrativa sobre compartilhar experiências humanas em escala global (RADISH, 2015) e na premissa ficcional que os criadores estabeleceram de que originalmente todos os seres humanos eram sensates (homo sensorium), sendo que alguns que não nasceram com tal capacidade, devido a mutações, tornaram-se eficientes assassinos (homo sapiens) e com o tempo suplantaram numericamente os sensates (STRACZYNSKI, 2015, 2016; RADISH, 2015). Nessas ideias e diretrizes, já é possível observar as correlações com uma das principais lições do mito do Andrógino que se consolida no roteiro: a necessidade de o ser humano buscar a completude no Outro, naquele que é diferente e que, justamente por isso, complementa algo que in illo tempore lhe foi tirado ${ }^{6}$.

Outro indício do processo de criação relacionado ao mitema da busca da completude está na etapa de filmagem. Para criar efeitos mais realistas de conectividade e fusão de personagens que se complementam, as gravações foram feitas nos locais aos quais eles pertenciam e também foram usados truques de câmera para criar as imagens de conexões entre os sensates em uma mesma cena ou sequência (ver making of sense8: Criação do Mundo). Em alguns casos há a gravação da mesma cena em diferentes locações, adicionando a cada uma delas um dos protagonistas locais. Assim, uma cena que contava com a interação de um personagem na América do Norte, outro na África e um terceiro na Europa, começava em Chicago, era filmada novamente em Nairóbi e mais uma vez em Berlim. O processo, que levou a gravação dos doze episódios a durar quatro meses,

6 Segundo o relato mítico apresentado por Platão na sua obra "O banquete", originariamente a raça humana era formada por seres andróginos: "essa criatura primordial era redonda: suas costas e seus lados formavam um círculo e ela possuía quatro mãos, quatro pés e uma cabeça com duas faces exatamente iguais, cada uma olhando numa direção, pousada num pescoço redondo". Ambiciosos, desafiaram os deuses e foram punidos com a sua separação em dois, tornando-se seres incompletos e em eterna busca pela metade perdida. 
resulta em imagens que materializam a ideia de completude expressa no roteiro e concorre para dar-lhes autenticidade e aspectos de diversidade.

Outra contribuição significativa para o processo de criação do mitema da busca da completude ocorre na etapa da edição, com a inserção de canções em momentos de inflexão da narrativa - fazendo algumas sequências aproximarem-se da linguagem do videoclipe - e enfatizando o tema da completude em diferentes perspectivas. No episódio 4, a canção What's up? (4nonBlondies) embala as imagens em que a completude se dá através do ligar entre os personagens, com a conexão entre eles preservando a individualidade de cada um. Trata-se da primeira sequência na série em que a conexão entre os sensates fica evidente. No episódio 6, a canção Demons (Fatboy Slim feat. Macy Gray) acompanha a sequência de imagens de orgia em que a completude se dá através do misturar, com a conexão entre os sensates ocorrendo como se fosse uma fusão completa entre os protagonistas envolvidos.

Por fim, na etapa de marketing, a ideia da busca da completude é reforçada nos trailers, especialmente na versão conceitual, veiculada nos Estados Unidos e Canadá, cujas imagens não só reforçam a ideia de conexão-complementação entre os personagens (Figura 6), como também remetem à imagem do Andrógino descrita por Platão e representada em artefatos da Grécia Antiga. Ela é reforçada também nas entrevistas de Straczynski em que ele enfatiza que a série parte do ensinamento de que "somos mais fortes juntos do que separados" (STRACZYNSKI, 2015, tradução nossa).

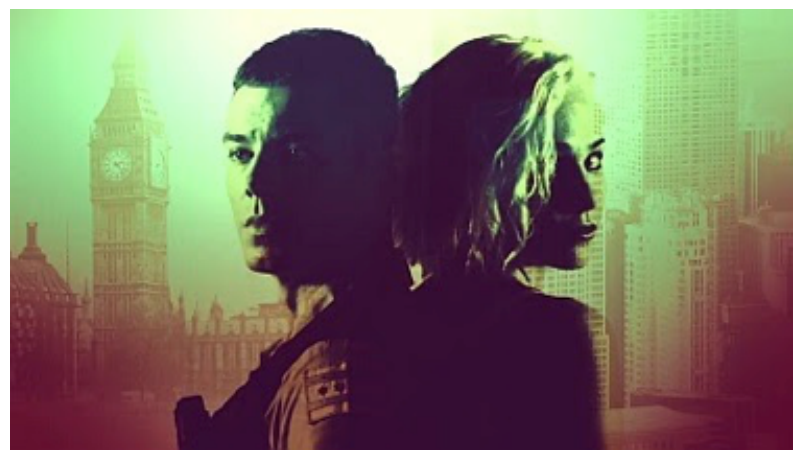

Fig.6. Imagem que remete à ideia de completude em trailer de sense8. Fonte: Trailer-conceito sense8 (Netflix, 2015).

O mitema da busca da completude, que é desenvolvido pelo roteiro e tem papel central na estrutura arquetípica em sense8, é materializado ao longo das etapas rotineiras de produção da narrativa, sendo possível identificar algumas pegadas mais específicas ao longo do processo criativo que marcam a sua construção. Os rastros identificados e descritos anteriormente estão sintetizados no diagrama a seguir (Figura 7), que mostra as contribuições registradas a cada etapa: 


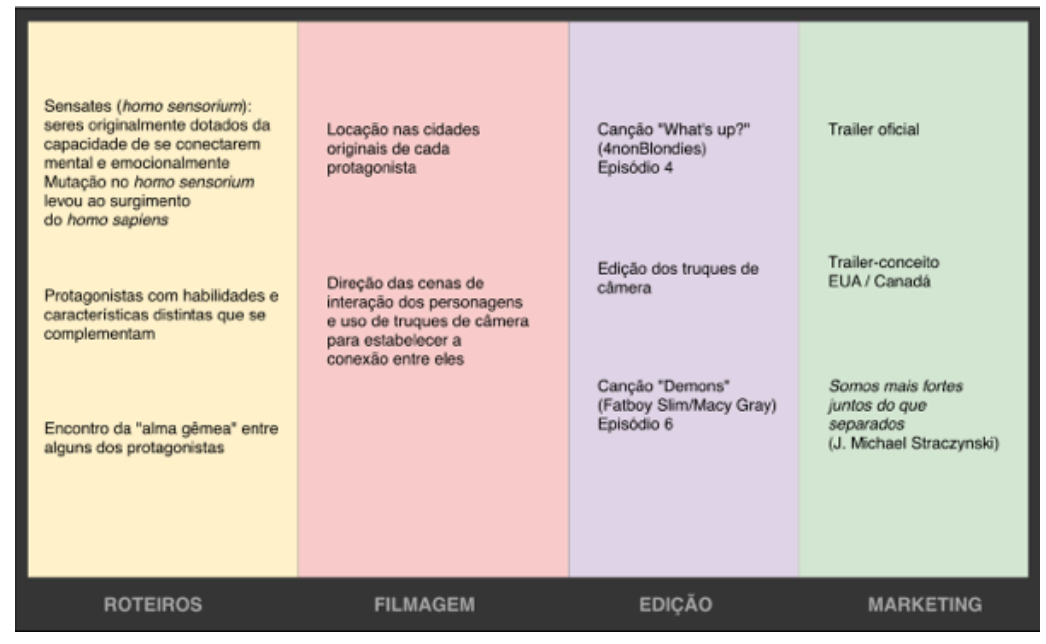

Figura 7: Rastros da criação do mitema busca pela completude em sense8.

Fonte: Elaborado pelo autor.

O procedimento de análise descrito neste capítulo deve ser aplicado a todos os mitemas encontrados na mitocrítica para obter-se um mapeamento completo do processo criativo da narrativa, a partir dos rastros deixados ao longo da criação do imaginário que emerge dela. Adotar o mitema como elemento básico no estudo do processo criativo da narrativa produzida pela indústria do audiovisual pode ser uma possibilidade eficiente para a análise da criação de filmes, séries, novelas e outros produtos audiovisuais.

\section{Considerações finais}

Este artigo desenvolveu três teses complementares para o estudo do processo de criação na indústria do audiovisual.

A primeira foi a de que, para dar conta da complexidade dessa indústria, composta por múltiplos colaboradores-criadores, em que a criação e produção das narrativas se dá de forma segmentada e interconectada e em que não há uma função que controle todas as etapas, a compreensão da dinâmica do processo criativo deve ser feita pelo estudo das transformações em dois ciclos: no de elaboração do roteiro e no de construção do imaginário da narrativa por meio da materialização do roteiro ao longo das etapas de filmagem, edição, marketing e transmídia. Essa dinâmica mostrou que o roteiro, como ponto de partida e espinha dorsal de todo o processo criativo, estabelece a estrutura arquetípica da narrativa que direciona as etapas seguintes de sua materialização em imagens e sons.

A segunda tese diz respeito justamente à estrutura arquetípica, que foi definida como a configuração que o conjunto de elementos simbólicos, dentre os quais destacam-se os arquétipos e estereótipos, com suas funções dramáticas e psicológicas, assume para 
contar uma determinada história e estabelecer o núcleo do imaginário que seu(s) criador(es) propõe $(\mathrm{m})$ compartilhar com a audiência. A tese é de que tal estrutura, que atravessa toda a narrativa e orienta também os subprodutos correlatos e transmidiáticos, tem o papel de estabelecer o(s) enredo(s) medular(es) da narrativa e os arquétipos e estereótipos que compõem o núcleo do imaginário e as suas conexões. Observou-se que parece ser característica frequente da estrutura arquetípica a reprodução ou atualização de um acervo restrito de protótipos de narrativas.

A terceira tese, construída com base na perspectiva heurística do imaginário (Durand), propôs o mitema como elemento básico para o estudo do processo de criação das narrativas audiovisuais. Isto é, partindo da premissa de que as narrativas têm nos mitos suas matrizes e que a mitocrítica possibilita identificar os mitos que assediam a narrativa por meio da identificação dos mitemas presentes nelas, a tese proposta foi a de que o estudo do processo de criação da narrativa audiovisual pode ser feito de forma eficiente pela investigação da construção dos mitemas ao longo das etapas de criação e produção.

Considerando os limites existentes na obtenção de documentos disponibilizados aos pesquisadores para o estudo do processo criativo na indústria do audiovisual, buscouse aqui desenvolver caminhos alternativos que deem indícios das ações que impactam na criação do produto.

Os rastros deixados nas versões dos roteiros e a comparação, quando possível, do roteiro inicial (first draft) com o produto final é uma possibilidade, mas ela não basta para dar conta de todo o processo, afinal a materialização do que está dado no roteiro ocorre em etapas em que o processo criativo continua a operar, especialmente na filmagem e edição. Buscar os rastros dos atos de criação nessas etapas é essencial para a compreensão ampliada do processo.

A proposta do uso do mitema como base da investigação desses rastros engendra um método de análise do processo criativo na indústria do audiovisual que sinaliza como uma alternativa nesse campo de estudo. A eficiência dessa proposta necessita, no entanto, ser amplamente testada.

Sílvio Antonio Luiz Anaz é pós-doutor em Meios e Processos Audiovisuais na Escola de Comunicações e Artes da USP. É pesquisador-visitante na School of Arts, Media, Performance \& Design da York University e doutor em Comunicação e Semiótica pela PUC-SP.

silvioanaz@hotmail.com 


\section{Referências}

ANAZ, S. Processo criativo no cinema mainstream na perspectiva da teoria do imaginário. In: LEÃO, L. (Ed.). Processos do imaginário. São Paulo: Képos, 2016.

BARROS, A.T.P. Comunicação e imaginários: algumas contribuições da Escola de Grenoble. In: LEÃO, L. (Ed.). Processos do imaginário. São Paulo: Képos, 2016.

BOOKER, C. The seven basic plots: why we tell stories. Londres e Nova York: Continuum, 2010.

CAMPBELL, J. O herói de mil faces. São Paulo: Cultrix/Pensamento, 1997.

DURAND, G. As estruturas antropológicas do imaginário: introdução à arquetipologia geral. São Paulo: Martins Fontes, 2002.

Sobre a exploração do imaginário, seu vocabulário, método e aplicações transdisciplinares.

Revista Faculdade de Educação da Universidade de São Paulo, n. 11 (1/2), p. 243-273, 1985.

O retorno do mito: introdução à mitodologia. Mitos e sociedades. Revista FAMECOS, Porto Alegre, n. 1, p. 7-22, set. 2004.

Passo a passo da mitocrítica. Revista Ao Pé da Letra, Universidade Federal de Pernambuco, v. 14, n. $2,2012$.

ELIADE, M. Mito do eterno retorno. São Paulo: Mercuryo, 1992.

Mito e realidade. São Paulo: Perspectiva, 1998.

FRYE, N.; MACPHERSON, J. Biblical and classical myths: the mythological framework of western culture. Toronto: University of Toronto Press, 2004.

HARK, H. (Org.). Léxico dos conceitos junguianos fundamentais: a partir dos originais de C. G. Jung. São Paulo: Edições Loyola, 2000.

JUNG, C. G. Arquétipos e inconsciente colectivo. Barcelona: Paidós, 1970.

PLATÃO. O banquete. São Paulo: Edipro, 2012.

PROPP, V. Morfologia do conto maravilhoso. São Paulo: Forense Universitária, 2006.

RADISH, C. 18 things to know about sense8. Collider. 4 jun. 2015. Disponível em: < http://collider. com/18-things-to-know-about-sense8/>. Acesso em: 17 maio 2017.

RICOEUR, P. Interpretação e ideologias. Rio de Janeiro: Francisco Alves, 1990.

SALLES, C. A. Comunicação em processo. Galáxia, n. 3. 2002, p. 61-71.

STRACZYNSKI, J. M. 'Sense8' co-creator J. Michael Straczynski on how Netflix's show changed him, and could change television. Entrevista para Liz Shannon Miller. IndiWire. 2015. Disponível em: $<$ http://www.indiewire.com/2015/06/sense8-co-creator-j-michael-straczynski-on-how-netflixs-showchanged-him-and-could-change-television-61203/>. Acesso em: 17 maio 2017.

"Both collaborative and challenging." Straczynski on sense8. Entrevista para Sam Roads.

Creative Screenwriting. 2016. Disponível em: <https://creativescreenwriting.com/sense8/>. Acesso em: 17 maio 2017.

VERNANT, J. P. O universo, os deuses, os homens. São Paulo: Companhia das Letras, 2000.

VOGLER, C. A jornada do escritor: estruturas míticas para escritores. Trad. Ana Maria Machado. Rio de Janeiro: Nova Fronteira, 2006. 


\section{Referências fílmicas}

BLADE RUNNER, O CAÇADOR DE ANDROIDES (Blade Runner). Ridley Scott. Estados Unidos: The Ladd Company, Tandem Productions, Sir Run Run Shaw. 1982.

GUERRA NAS ESTRELAS; UMA NOVA ESPERANÇA (Star Wars: A New Hope). George Lucas. Estados Unidos: Lucas Film Production. 1977.

SENSE8 (sense8). The Wachowsky; J. Michael Straczynski. Estados Unidos. Netflix. 2015.

Artigo recebido em 18 de maio e aprovado em 26 de setembro de 2017. 